\title{
Automedicação, Custos e Saúde
}

VASCO A. J. MARIA

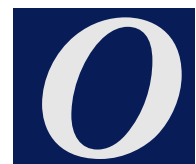

s Clínicos Gerais/Médicos de Família são responsáveis pela prescrição de uma parte considerável dos medicamentos consumidos em Portugal. De facto, a prescrição de um ou mais medicamentos constitui um acto frequente com que o Médico de Família termina a consulta. ${ }^{1}$

Por outro lado, os custos com medicamentos continuam a crescer, apesar de algumas iniciativas para conter esse crescimento como sejam, o desenvolvimento e utilização de orientações terapêuticas e a adopção de formulários mais ou menos restritivos.

Apesar da importância dos problemas associados à prescrição e utilização de medicamentos, são escassos ou de interesse limitado, os trabalhos de investigação realizados em Portugal nesta área.

O estudo de Marques e col., publicado no presente número da Revista, ${ }^{2}$ constitui uma notável excepção e ganha relevância acrescida porquanto incide sobre um problema importante da prática clínica. De facto, a automedicação tem implicações clínicas, económicas, éticas e socioculturais consideráveis e levanta questões importantes relacionadas com a utilização racional dos medicamentos, a educação para a saúde e os direitos individuais e colectivos.

$\mathrm{O}$ estudo analisou a dispensa de medicamentos durante um dia em 21 farmácias da Região Centro do País com o objectivo de caracterizar a natureza e os custos financeiros directos da au-

Director da Revista Portuguesa de Clínica Geral tomedicação. Os autores identificaram um total de 2053 atendimentos, sendo $31,6 \%$ relacionados com automedicação.

É importante notar que o estudo foi realizado durante os meses de Julho e Agosto. A inclusão dos meses de Inverno no estudo teria como resultado uma frequência de situações de automedicação provavelmente bastante superior, dada a maior frequência de afecções com manifestações susceptiveis de induzir uma maior procura.

Um resultado importante a destacar neste estudo é o facto de $34 \%$ das embalagens fornecidas pelas farmácias sem prescrição médica estarem, de facto, abrangidas pelo estatuto legal de "sujeitas a receita médica obrigatória". Destas embalagens, $18 \%$ foram dispensadas em situações em que o motivo da procura foi a apresentação de queixas e resultaram, presumivelmente, da iniciativa do farmacêutico ou ajudante de farmácia.

Deste modo, teria sido interessante caracterizar as atitudes dos farmacêuticos e ajudantes de farmácia face à apresentação de queixas e à solicitação explícita de medicamentos sujeitos a receita médica obrigatória por parte dos utentes.

Estudos realizados em outros países europeus dão ideia da importância crescente deste problema. Um estudo realizado recentemente em Espanha mostrou que a automedicação com antibióticos ocorreu em 32\% dos individuos que adquiriram um antibiótico em farmácias. ${ }^{3}$ Em $20 \%$ dos casos a automedicação foi da responsabilidade do próprio doente e em $12 \%$ da responsabilidade do farmacêutico ou ajudante de 
farmácia.

Em muitos países ocidentais assiste-se actualmente a uma tendência para a mudança de estatuto de medicamentos sujeitos a receita médica para não sujeitos a prescrição.

Paralelamente, verifica-se uma alteração no comportamento dos consumidores no sentido da automedicação. O envolvimento dos doentes nas decisões terapêuticas é, em geral, considerado como um factor importante no processo terapêutico. Um grau de envolvimento elevado pressupõe maior e melhor informação e, portanto, maior probabilidade de utilização adequada dos medicamentos. ${ }^{4}$

A prática da automedicação pode traduzir-se numa redução significativa da carga de trabalho do médico, como consequência de uma menor procura de consultas para resolução de problemas de saúde menores e autolimitados e, simultaneamente, numa redução dos custos com medicamentos.

Contudo, a prática da automedicação não está isenta de riscos, particularmente no que se refere a determinados grupos terapêuticos. ${ }^{5}$ Em primeiro lugar, existe a possibilidade de o recurso à automedicação poder mascarar doenças graves, com o consequente atraso no diagnóstico ou prejuízo no seguimento médico de situações potencialmente graves. Existe, ainda, a possibilidade de utilização inadequada dos medicamentos por parte de alguns doentes, nomeadamente, doentes idosos ou com défices cognitivos significativos. Também a interacção entre medicamentos prescritos e não prescritos é uma possibilidade que não pode ser esquecida.

Deste modo, é legítima a preocupação de alguns profissionais de saúde pelo facto de a utilização de medicamentos razoavelmente potentes poder escapar à vigilância médica. Por outro lado, a promoção da automedicação na perspectiva estrita da contenção dos custos pode, em algumas circunstâncias, acabar por ter efeitos perversos, na medida em que os custos a longo prazo podem acabar por exceder os potenciais beneficios. ${ }^{6}$

O papel do Farmacêutico Comunitário pode ser de grande importância para o Médico de Família na sua prática clínica, permitindo uma redução significativa da carga de trabalho e favorecendo uma melhor utilização dos recursos disponíveis.

A este respeito, existe alguma evidência que as potencialidades da utilização de medicamentos sem prescrição médica não têm sido aproveitadas da melhor maneira por médicos e farmacêuticos. ${ }^{7}$

No seu papel como prestador de cuidados primários, o Farmacêutico Comunitário deve ter a capacidade de avaliar se os medicamentos dispensados em regime de automedicação vão aliviar os sintomas do doente ou se este requer referenciação ao médico para avaliação e tratamento mais adequados.

Na perspectiva do Médico de Família, o estabelecimento de um sistema de refe-renciação de duas vias deve permitir tirar partido do Farmacêutico Comunitário como perito na utilização de medicamentos sem receita médica, assegurando, por outro lado, uma via através da qual o farmacêutico pode referenciar ao médico os doentes com situações potencialmente graves.

A Directiva Europeia que regulamenta o estatuto de dispensa dos medicamentos, estabelece que estes deverão ser de receita médica obrigatória se: i) têm riscos significativos para a saúde se usados na ausência de supervisão médica; ii) são com frequência usados incorrectamente; iii) são de aprovação recente ou necessitam de investigação adicional; iv) são administrados por via injectável.

Os medicamentos dispensados sem receita médica obrigatória são considerados razoavelmente seguros mas não 
desprovidos de riscos e a sua utilização significa que os doentes assumem uma responsabilidade acrescida quanto à própria saúde e aos riscos que daí possam advir.

Aumentar o número de medicamentos sem receita médica pode significar aumentar o risco de interacções e reacções adversas. Deste modo, é fundamental promover a utilização racional dos medicamentos junto dos consumidores e desenvolver e utilizar sistemas eficientes de informação e de comunicação entre médico e farmacêutico, com o objectivo de maximizar os beneficios e reduzir a um minimo aceitável os riscos inerentes à utilização dos medicamentos. ${ }^{8,9}$

O cumprimento deste desiderato implica uma responsabilidade acrescida por parte dos profissionais de saúde, nomeadamente, Médicos de Família e Farmacêuticos Comunitários.

\section{REFERÊNCIAS BIBLIOGRÁFICAS}

1. Maria VAJ, Carvalho ML, Pimpão MV Azevedo JS, Carreira MA, Victorino RM. Estudo clínico-epidemiológico de Reacções Adversas a Medicamentos em Cuidados de Saúde Primários. Arq Saúde Pública 1988; XIII: 145-72.

2. Marques FB, Cobrado N, Caramona M. Caracterização da natureza e dos custos financeiros directos da automedicação. Rev Port Clin Geral 2000; 16:23-34

3. Gonzales OA, Lozano MA, Nunes J. Analysis de automedication con antibioticos en España. Enferm Infecc Microbiol Clin 1998; 16: 328-33.

4. Gore P, Madhavan S, McClung G, Riley D. Consumer involvement in nonprescription medicine purchase decisions. J Health Care Mark 1994; 14: 16-23.

5. Bradley $\mathrm{CP}$, Bond C. Increasing the number of drugs available over the counter. Arguments for and against. $\mathrm{Br} \mathrm{J}$ Gen Pract 1995; 45: 553-6.

6. Rubin N, Foxman B. The cost-effectiveness of placing urinary tract infection treatment over the counter. J Clin Epidemiol 1996;
49: 1315-21.

7. Li Wan Po A, Su XY. Over the counter drugs. Both doctors and pharmacists should prescribe better. BMJ 1996; 313: 115.

8. Bond CM, Bradley C. Over the counter drugs. The interface between the community pharmacist and patients. BMJ 1996; 312: 75860.

9. Thomas DH, Noyce PR. The interface between self medication and the NHS. BMJ 1996; 312: 688-91. 